\title{
Atypical forms of Cryptococcus neoformans in CSF of an AIDS patient
}

\author{
Javier Bava ${ }^{1}$, Ruben Solari ${ }^{2}$, Guillermina Isla ${ }^{3}$, Alcides Troncoso ${ }^{4}$ \\ ${ }^{1}$ Mycology, University of La Plata, Buenos Aires, Argentina \\ ${ }^{2}$ Infectious Diseases "Francisco J. Muñiz" Hospital, Buenos Aires, Argentina \\ ${ }^{3}$ Department of Mycology, ANLIS "Carlos Malbrán", Buenos Aires, Argentina \\ ${ }^{4}$ Microbiology \& Parasitology and Infectious Diseases, School of Medicine, Buenos Aires University, Buenos Aires, Argentina
}

\begin{abstract}
The microscopic recognition of typical rounded capsulated yeasts in centrifuged cerebrospinal fluid (CSF), stained with India ink, is a common, rapid and effective method for the diagnosis of cryptococcal meningitis among AIDS patients. The presence of atypical forms of Cryptococcus neoformans var. neoformans in samples of CSF of an AIDS patient with cryptococcosis treated at the University Hospital of Infectious Disease is presented. The India ink microscopy of three consecutive CSF samples revealed capsulated yeast with India ink particles in the deteriorated capsules and capsulated pseudohyophae. Clinically, the patient showed a subacute meningoencephalitis, with a clinical picture not particularly different from those commonly observed in patients with AIDS-associated cryptococcosis treated in our hospital. In all cases, the culture of the CSF showed colonies of $C$. neoformans with typical macro and micromorphology, and the in vitro susceptibility tests to amphotericin B, fluocitosine, itraconazole and fluconazole showed MIC values into the limits of sensitivity. The presence of atypical forms of $C$. neoformans, considered as an atypical finding, could be the consequence of an adaptive phenomenon of this fungal species to an impaired immunological status present in the host.
\end{abstract}

Key Words: Cryptococcosis, microscopy for yeast, atypical micromorphology

J Infect Developing Countries 2008; 2(5):403-405.

Received 10 April 2008 - Accepted 30 June 2008

Copyright ( $) 2008$ Bava et al. This is an open access article distributed under the Creative Commons Attribution License, which permits unrestricted use, distribution, and reproduction in any medium, provided the original work is properly cited.

\section{Introduction}

Cryptococcosis is the most frequent systemic mycosis among AIDS patients, with prevalence between $5 \%$ to $25 \%$ according to geographical regions [1]. It produces principally acute or subacute meningitis or meningoencephalitis, depending on the immunologic status of the patients, and it requires immediate antifungal treatment [2]. The diagnosis of cryptococcosis is more frequently achieved by searching the typical rounded capsulated yeast of Cryptococcus neoformans in the CSF stained with India ink [3].

Cryptococcus culture is a highly sensitive diagnostic test that can isolate the Cryptococcus strain for identification and further in vitro antifungal susceptibility tests [4)] In patients with both AIDS and cryptococcosis, diagnosis is rarely performed by searching for the capsular antigen of $C$. neoformans in the CSF (or other biological fluids) because of the highly sensitive and specific nature of the microscopy and culture assays [5].

The presence of atypical microscopic forms of $C$. neoformans in the CSF concentrate must be considered as a rare finding in AIDS patients with cryptococcosis, at least in our experience.

\section{Case Report}

The patient, a 34-year-old heterosexual male intravenous drug user, was diagnosed as HIV positive in 1989. He was admitted in the Muñiz Hospital in June of 2007 with headache, photophobia, vomiting, asthenia, and altered sensory perception.

Several months previous to this admission, e had received complete treatment with fluoroquinolone, cycloserine, ethambutol and ethionamide for pulmonary tuberculosis produced by a multi-resistant strain. $\mathrm{He}$ had also received an incompleted treatment for episodes of cryptococcal meningitis. The antiretroviral schedules (stavudine, lamivudine and efavirenz) were performed incompletely in 1999 for only 20 days before they were finally discontinued (.

At admission, the patient'speripheral blood showed a CD4+ T lymphocyte count of 67 cells/ $\mu \mathrm{L}$, and a viral load of 44.475 copies $/ \mathrm{ml}$ by a signal amplification nucleic acid probe assay (Versant ${ }^{\circledR}$ HIV - 1 RNA 3.0 Assay bDNA, Semens Healthcare Diagnostics Inc.), as 
an indirect markers of the immunology impairment produced by the HIV infection.

The diagnosis of cryptococcosis in the present episode was made by microscopy with India ink and cultures of CSF. Two other samples of the same fluid, obtained to reduce intracranial pressure, were also mycologically studied. Immediately after the mycological diagnosis, the patient received intravenous amphotericin B, $1 \mathrm{mg} / \mathrm{kg}$ (IV) $\mathrm{q} 24 \mathrm{~h}$, which is the protocol in our hospital for this mycosis [6].

The patient clinically evolved without a positive response to the antifungal treatment with amphotericin deoxicholate, then was switched to amphotericin B colloidal dispersion at the fifth day of admission. The patient died 10 days post-admission.

Three CSF samples were obtained, the first at diagnosis and then at three and five days post-diagnosis. Microscopy of the first CSF sample revealed the presence of rounded and capsulated yeast with India ink particles in the deteriorate capsules, as observed in the Figure 1. The second and third samples contained a large number of capsulated pseudohyphae accompanied by predominant rounded and capsulated yeast, as is observed in Figure 2.

Figure 1. Concentrated CSF stained with India ink showing yeast with deteriorated capsules (400X).

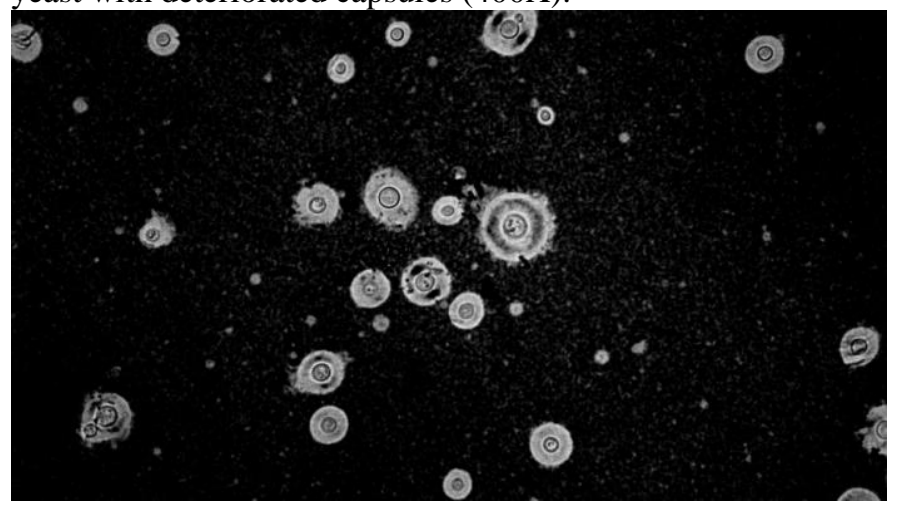

The culture of the CSF samples on Sabouraud dextrose agar and Sunflower seed agar [7] at $28^{\circ} \mathrm{C}$ and $37^{\circ} \mathrm{C}$ showed colonies of $C$. neoformans with typical macro and micromorphology; all were identified as $C$. neoformans var. neoformans, using the CGB media [8].

When were compared, the growth time, fenol oxidase production and capsule size of the isolated strains were similar to $C$. neoformans strains from other patients with AIDS-associated cryptococcosis treated in the Muñiz Hospital (unpublished data).

The values of MIC of the isolated strains to amphotericin B $(0.25 \mu \mathrm{g} / \mathrm{ml})$, fluocitosine $(4 \mu \mathrm{g} / \mathrm{ml})$, itraconazole $(<0.015 \mu \mathrm{g} / \mathrm{ml})$ and fluconazole $(8 \mu \mathrm{g} / \mathrm{ml})$, performed by the method of microdilution in plates, were all within the susceptibility range (4).

Figure 2. Capsulated seudohypha and budding yeast in the CSF concentrate stained with India ink (400X).

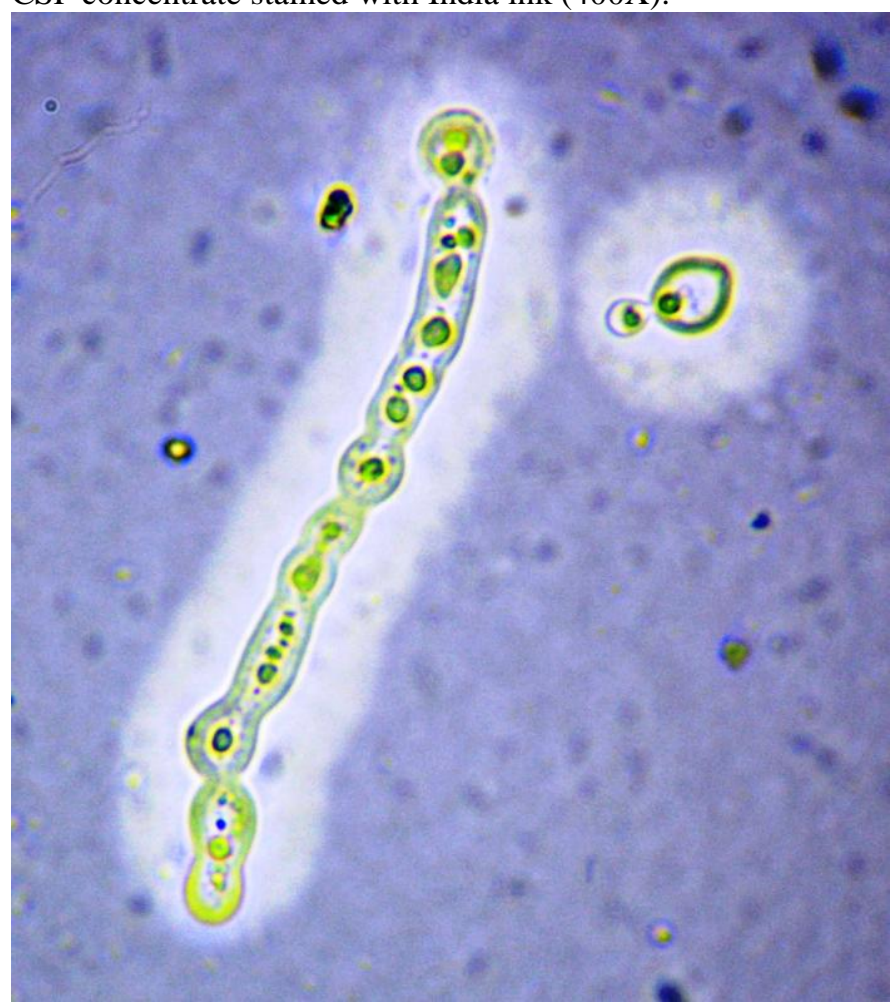

\section{Discussion}

The presence of atypical forms of $C$. neoformans in the CSF of AIDS patients with cryptococcosis could be interpreted as a possible adaptation of the fungal cells to the media. The pseudohyphae could be hypothetically considered as a virulence factor, as it was established for Candida albicans, to avoid the phagocytosis by specialised cells in the CNS.

Although the pseudohyphae were not predominant in the studied samples, this phenomenon was probably observed when only a few cells had produced these structures. The great immunological deficit and the further clinical evolution could induce a better ability of the fungal cells to produce pseudohyphae instead of the traditional yeasts.

The influence of the immunology status on this phenomenon is sustained by the fact that no special mycological proprieties (phenoloxidase production, growth rate or capsule size) were observed in the strain isolated from the patient. We are not able to explain the presence of damaged capsules in one CSF sample and pseudohyphae in others, obtained after only a few days. 
On the other hand, damaged capsules could be the result of the antifungal activity of amphotericin $\mathrm{B}$, which was observed by us in CSF from other AIDS patients with cryptococcosis treated with this polyene. Probably, the incomplete and discontinuous antifungal treatments received during several episodes of cryptococcal meningitis could be the reason for these changes. However, these abnormalities are not observed in most patients with AIDS-associated cryptococcosis and in the present case are not related to any particular clinical or mycological findings. The clinical picture of this patient was not different from those observed in other AIDS patients with Cryptococcal meningitis treated in the Muñiz Hospital [9]

Previously, other authors referred to atypical forms of C. neoformans in CSF and tissues. Williamson et al. observed chains of budding yeasts, germ tubes, and pseudohyphae in the CSF of five AIDS patients with cryptococcosis as well as in histopathological sections of other organs, one in a brain biopsy, and the other in the pleural fluid of a patient with non-Hodgkin lymphoma [10].

Cruickshank et al. communicated the presence of abnormally large yeasts of $C$. neoformans in a patient with pulmonary cryptococcosis, which produced macro and micromorphologically normal colonies [11].

While Lurie and Shadomy described true hyphaeproducing strains of $C$. neoformans in the tissues of experimentally infected mice (12), Neilson et al. observed the absence of cerebral lesions and yeasts in mice inoculated with forming pseudohyphae strains of C. neoformans [13].

Although we are not able to establish an association between the presence of atypical forms of $C$. neoformans in CSF and any clinical or mycological picture in the patients, we speculate that these forms could be present in different clinical samples and especially in CSF, most frequently processed for the diagnosis of cryptococcosis.

If clinical findings suggest cryptococcosis, additional specimens should be tested even though the initial specimen is negative. Atypical forms of $C$. neoformans and other fungal agents must be recognised by microbiologists and their presence must be included in the report, although the habitual forms achieve the diagnosis.

\section{Acknowledgements}

We acknowledge Dr. Marcela Witt for his assistance in the revision of this paper.

\section{References}

1. Mitchell TG, Perfect JR (2003) Cryptococcosis in the era of AIDS-100 years after the discovery of Cryptococcus neoformans. Clin Microbiol Rev 8:515-548.

2. Rozenbaum R, Goncalves AJ (1994) Clinical epidemiological study of 171 cases of cryptococcosis. Clin Infect Dis 18: 369380 .

3. Arechavala AI, Robles AM, Negroni R, Bianchi M, Taborda A (1993) Valor de los metodos directos e indirectos de diagnóstico en las micosis sistémicas asociadas al SIDA. Rev. Inst. Med. Trop. Säo Paulo 35: 163-169.

4. Sheehan DJ, Espinel-Ingroff A, Moore LS, Webb CD (1992) Antifungal susceptibility testing of yeasts: a brief overview. Clin Infect Dis 17 Suppl 2: S494-500.

5. Tanner DC, Weinstein MP, Fedorciw B, Joho KL, Thorpe JJ, Reller L (1994) Comparison of commercial kits for detection of cryptococcal antigen. J Clin Microbiol 32: 1680-1684.

6. Negroni R, Arechavala AI, Robles AM, Bava AJ, Helou S (1995) Revisión clínica y evolución terapéutica de pacientes con criptococosis asociada al SIDA. Rev Iberoam Micol 12: 12-15.

7. Pal M., Mehrotra BS (1982) Studies on the efficacy of sunflower seed agar for the isolation and identification of Cryptococcus neoformans Arogya. J. Health Sci. 8:74-79.

8. Kwon Cheng KJ, Polacheck I, Bennett JE (1993) Improved diagnostic medium for separation of Cryptococcus neoformans varieties. J Clin Microbiol 32: 253-255.

9. Bava AJ, Arechavala, Negroni R, Robles AM, Bianchi M (1997) Cryptococcosis associated with AIDS in the Muñiz Hospital of Buenos Aires. Mycopathologia (Deen Haag) 140; 13-17.

10. Williamson JD, Silverman JF, Mallak CT, Christie JD (1996) Atypical cytomorphologic appearance of Cryptococcus neoformans: a report of five cases. Acta Cytol 40: 363-370.

11. Cruickshank JG, Cavill R, Jelbert M (1973) Cryptococcus neoformans of unusual morphology. Appl Microbiol 25: 309312.

12. Lurie HI, Shadomy HJ (1971) Morphological variations of a hypha-forming strain of Cryptococcus neoformans (Coward strain) in tissues of mice. Sabouraudia. 9: 10-14.

13. Neilson JB, Fromtling RA, Bulmer GS (1981) Pseudohyphal forms of Cryptococcus neoformans: decreased survival in vivo. Mycopathologia 73: 57-59.

Corresponding Author: Amadeo J. Bava, Cordoba 4441, $4^{\mathrm{o}}$ "20", Buenos Aires, República Argentina

E-mail: javibava@biol.unlp.edu.ar

Conflict of interest: No conflict of interest is declared. 